\title{
Current Topics in Medical Mycology
}




\section{Editorial Board}

Libero Ajello, Ph.D., Director, Division of Mycotic Diseases, Centers for Disease Control, Atlanta, Georgia 30333, USA

Garry T. Cole, Ph.D., Professor, Department of Botany, The University of Texas at Austin, Austin, Texas 78712, USA

Rebecca A. Cox, Ph.D., Director, Research Immunology, San Antonio State Chest Hospital, San Antonio, Texas 78223, USA

David J. Drutz, M.D., Vice President, Biological Sciences, Smith, Kline and French Laboratories, Swedeland, Pennsylvania 19479, USA

R. J. HAY, D.M., M.R.C.P., Senior Lecturer in Clinical Mycology, London School of Hygiene and Tropical Medicine, London WC1E 7HT, United Kingdom

Kazuo Iwata, M.D., Professor and Chairman, Department of Microbiology, Meiji College of Pharmacy, Setagaya-ku, Tokyo, 154, Japan

George S. Kobayashi, Ph.D., Professor, Division of Dermatology, Washington University School of Medicine, St. Louis, Missouri 63110, USA

C. P. Kurtzman, Ph.D., Research Leader, Culture Collection Research, Fermentation Laboratory, USDA-ARS, Northern Regional Research Center, Peoria, Illinois 61604, USA

Thomas G. Mitchell, Ph.D., Department of Microbiology and Immunology, Duke University Medical Center, Durham, North Carolina 27710, USA

Richardo Negroni, M.D., Professor and Director, Catedra de Microbiologica, Parasitologia e Immunologia, Centro de Micologia, Buenos Aires, Argentina

ERrol Reiss, Ph.D., Research Microbiologist, Division of Mycotic Diseases, Centers for Disease Control, Atlanta, Georgia 30333, USA

John L. RichaRd, Ph.D., Research Leader, Mycoses and Mycotoxicoses, USDA-ARS, National Animal Disease Center, Ames, Iowa 50010, USA 


\section{Michael R. McGinnis Marcel Borgers}

Editors

\section{Current Topics in Medical Mycology VOLUME 3}

With 93 Illustrations

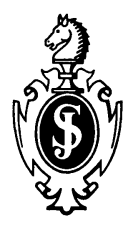

Springer-Verlag

New York Berlin Heidelberg

London Paris Tokyo Hong Kong 
Michael R. McGinnis, Ph.D.

Professor and Vice Chairman

Department of Pathology

University of Texas

Medical Branch

Galveston, Texas 77550

USA

Marcel Borgers, Ph.D.

Life Sciences

Janssen Research Foundation

Janssen Pharmaceutica

B-2340 Beerse

Belgium

Series Editor: Michael R. McGinnis

\section{ISSN 0177-4204}

(C) 1989 by Springer-Verlag New York Inc.

Sof tcover reprint of the hardcover 1st edition 1989

All rights reserved. This work may not be translated or copied in whole or in part without the written permission of the publisher (Springer-Verlag, 175 Fifth Avenue, New York, NY 10010, USA), except for brief excerpts in connection with reviews or scholarly analysis. Use in connection with any form of information storage and retrieval, electronic adaptation, computer software, or by similar or dissimilar methodology now known or hereafter developed is forbidden.

The use of general descriptive names, trade names, trademarks, etc. in this publication, even if the former are not especially identified, is not to be taken as a sign that such names, as understood by the Trade Marks and Merchandise Marks Act, may accordingly be used freely by anyone.

While the advice and information in this book are believed to be true and accurate at the date of going to press, neither the authors nor the editors nor the publisher can accept any legal responsibility for any errors or omissions that may be made. The publisher makes no warranty, express or implied, with respect to the material contained herein.

Typeset by Asco Trade Typesetting Ltd., Hong Kong. 


\section{Series Preface}

Current Topics in Medical Mycology, is intended to summarize current research areas in medical mycology for medical mycologists and other scientists who are working in microbiology and immunology. Topics to be included in each volume will serve as contemporary reviews, summaries of current advancements and future directions, and mechanisms to enhance the interdisciplinary use of medically important fungi in understanding pathogenesis, epidemiology, mycotoxins, taxonomy, and other areas where basic, applied, and clinical sciences are used.

Michael R. McGinnis

Marcel Borgers 


\section{Contents}

Series Preface v

Contributors ix

1 Animal Models for Dermatomycotic Infections JAN VAN CUTSEM

2 Vaccines for the Management of Dermatophyte and Superficial Yeast Infections

ESTHER SEgAL

3 Tissue-Bound Immunity: A Mechanism of Candidacidal Activity Hisashi Takahashi, Kenichiro ChikaKane, Masaru Okuda, Mariko Hatano, Manabu Hoshino, Osamu Kaneko, and Yoko Kawa

4 Rhinosporidiosis

Merani ThianPrasit and Kleophant

THAGERNGPOL

5 Pathogenesis of Candida Vulvovaginitis JACK D. SOBEL

6 Control of Extension of the Hyphal Apex NeIL A.R. Gow

7 Epidemiology and Ecology of Pityriasis Versicolor JAN FAERGEMANN

8 Fungal Cell Wall Synthesis and Assembly José Ruiz-Herrera, Rafael SENTANDreu 
9 Lipids and Lipoidal Mycotoxins of Fungi Michael A. Gealt, Abbas Abdollahi, and JOSEPH L. EVANS

10 Cell Wall of Candida albicans: Its Functions and Its Impact on The Host

Antonio Cassone

11 Regulation of Candida albicans Populations in the Gastrointestinal Tract: Mechanisms and Significance in GI and Systemic Candidiasis MichaEL J. KenNEDY

12 Antifungal Drug Susceptibility Testing DAVID W. WARNOCK

Index 


\section{Contributors}

Abbas Abdollahi, Ph.D.

Department of Bioscience and Biotechnology, Drexel

University, Philadelphia, PA 19104, USA

Antonio Cassone, M.D.

Director of Research, Istituto Superiore Di Sanita, Professor of Medical Microbiology, University of Rome, 00161 Rome, Italy

Kenichiro Chikakane, M.D.

Professor, Department of Dermatology, Teikyo University School of Medicine, Tokyo, 173, Japan

Joseph L. Evans, M.D.

Department of Medicine, Endocrine Metabolism Division, Dartmouth Medical School, Hanover, NH 03756, USA

Jan Faergemann, M.D.

Associate Professor of Dermatology, Department of Dermatology, University of Gothenburg, Sahlgren's Hospital, S-413 19 Gothenburg, Sweden

Michael A. Gealt, Ph.D.

Associate Professor of Biological Sciences, Drexel University, Philadelphia, PA 19104, USA

NeIl A.R. Gow, Ph.D.

Lecturer in Microbiology, Department of Genetics and Microbiology, University of Aberdeen, Aberdeen, AB9 1AS, England

Mariko Hatano, M.D.

Professor, Department of Dermatology, Teikyo University School of Medicine, Tokyo, 173, Japan 
Manabu Hoshino, M.D.

Professor, Department of Dermatology, Teikyo University

School of Medicine, Tokyo, 173, Japan

Osamu Kaneko, M.D.

Professor, Department of Dermatology, Teikyo University

School of Medicine, Tokyo, 173, Japan

Yoko Kawa, M.D.

Professor, Department of Dermatology, Teikyo University

School of Medicine, Tokyo, 173, Japan

Michael J. Kennedy, Ph.D.

The Upjohn Company, Kalamazoo, MI 49001, USA

Masaru OKuda, M.D.

Professor, Department of Dermatology, Teikyo University

School of Medicine, Tokyo, 173, Japan

José Ruiz-Herrera, Ph.D.

Professor and Director, Instituto de Investigacion Biologia

Experimental, Universidad de Guanajuato, Guanajuato, 36000, Mexico

Esther Segal, Ph.D.

Associate Professor, Microbiology/Mycology, Department of Human Microbiology, Sackler School of Medicine, Tel-Aviv University, Tel-Aviv 69978, Israel

Rafael Sentandreu, M.D.

Unidad de Microbiologia, Facultat de Farmacia, Universitat De Valencia, 46010 Valencia (l'Horta), Spain

JACK D. Sobel, M.D.

Professor of Medicine, Division Chief Infectious Diseases, Department of Medicine, Wayne State University School of Medicine, Detroit, MI 48201, USA

Hisashi TAKaHASHI, M.D.

Professor, Department of Dermatology, Teikyo University School of Medicine, Tokyo, 173, Japan

Kleophant ThagerngPol, MSC

Associate Professor, Department of Pathology, Siriraj Hospital, Mahidol University, Bangkok 10700, Thailand

Merani Thianprasit, M.D.

Professor of Dermatology, Division of Dermatology, Department of Medicine, Siriraj Hospital, Mahidol University, Bangkok 10700, Thailand 
Jan VAN Cutsem, M.D.

Director, Department Bacteriology and Mycology, Janssen Pharmaceutica, B-2340 Beerse, Belgium

David W. Warnock, Ph.D.

Top Grade Scientist, Department of Microbiology, Briston Royal Infirmary, Bristol, B52 8HW, England 